\title{
Comparison of Clinical Outcome between Craniectomy and Craniotomy as Surgical Management of Traumatic Acute Subdural Hematoma: A Systematic Review and Meta-analysis
}

\author{
Tjokorda Gde Bagus Mahadewa ${ }^{1 *}$, Putu Eka Mardhika , Sri Maliawan ${ }^{1}$, Nyoman Golden ${ }^{1}$, Steven Awyono ${ }^{1}$, Christopher Ryalino $^{2}$ \\ ${ }^{1}$ Department of Neurosurgery, Faculty of Medicine, Udayana University, Bali, Indonesia; ${ }^{2}$ Department of Anesthesiology, \\ Faculty of Medicine, Udayana University, Bali, Indonesia
}

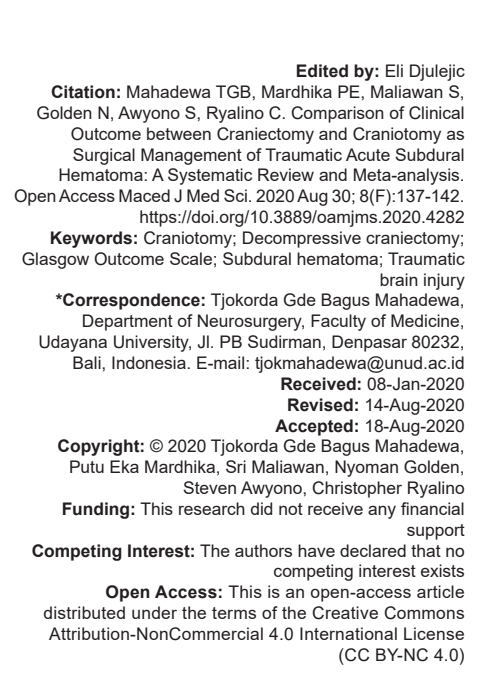

Abstract

BACKGROUND: Acute subdural hematoma $(\mathrm{ASDH})$ is a major problem in traumatic brain injury. Surgical techniques for treating ASDH are varied, including cranioplastic craniotomy and large decompressive craniectomy. The superiority of craniectomy and craniotomy for treating ASDH is still controversial.

AIM: The aim of this study was to compare the clinical outcome between craniectomy and craniotomy for treating traumatic ASDH through systematic review and meta-analysis.

METHODS: This study used electronic articles published in PubMed, EBSCO, Google Scholar, and Directory of Open Access Journal. Articles included were full-text observational studies in Indonesian or English. Clinical outcome using the Glasgow Outcome Scale was compared between craniectomy and craniotomy. Statistical analysis was done using Review Manager 5.3.

RESULTS: Six articles met our inclusion and exclusion criteria. We performed random effect model analysis because of high heterogeneity between studies $\left(I^{2}=77 \% ; X^{2}=21.98\right)$. The pooled risk ratio between craniectomy and craniotomy on poor outcomes was $1.41(p=0.02 ; 95 \% \mathrm{Cl}$ : 1.06-1.88).

CONCLUSION: Craniectomy increases the risk of poor clinical outcomes in treating a traumatic ASDH.

\section{Introduction}

Traumatic brain injury (TBI) is one of the major causes of mortality and permanent disability around the world. TBI is a spectrum of conditions ranging from a cerebral contusion to large intracranial hematoma [1]. Acute subdural hematoma (ASDH) is one of the major problems in TBI [2]. It is diagnosed with head CT scan as an extra-axial, crescentic hyperdense lesion between dura mater and brain parenchyma [2]. ASDH is a space-occupying lesion that increases intracranial pressure and usually accompanies with diffuse injuries, cerebral contusion, and edemas. Because of this, the mortality of ASDH remains high [2].

Management of ASDH is including operative and non-operative treatment. Non-operative management correlates with significantly higher mortality if compared to surgical management [3].
Surgical techniques for treating ASDH are varied. They include craniotomy and followed by cranioplasty, decompressive craniectomy, trephination/craniotomy, or combination of these procedures. Principally, the aim of the surgery is to relieve the brain from intracranial hypertension because of space-occupying lesion by the hematoma [4], [5]. Large craniotomy with hematoma evacuation could be a perfect choice to treat ASDH. However, when intraoperative brain swelling develops, decompressive craniectomy may be a better choice. However, based on a recent study in animals, bony decompression of the brain results in a reduction of intracranial pressure but enhances cold injury brain edema [4].

Based on what has been described, the superiority of craniectomy and craniotomy for treating ASDH is still controversial. This study aimed to compare the clinical outcome between craniectomy and craniotomy for treating traumatic ASDH through systematic review and meta-analysis. 


\section{Methods}

\section{Eligibility criteria}

Eligibility criteria were created based on the PICO framework. PICO criteria are shown in Table 1.

Table 1: PICO criteria of the study

\begin{tabular}{ll}
\hline Patient & Traumatic ASDH \\
Intervention & Decompressive craniectomy \\
Comparator & Craniotomy \\
Outcome & Glasgow Outcome Scale \\
\hline
\end{tabular}

This review included all studies comparing decompressive craniectomy and craniotomy in traumatic ASDH patients. We exclude review, animal, anatomic, cadaveric, qualitative, and economic studies. Articles made by the same author in the same institution were performed sample evaluation to prevent sample duplication. We included studies published in Indonesian and English. Other languages were translated using Google translate and decided by author whether include them or not. There was no restriction regarding the year of publication.

This review included studies with adult participants (age 18 years or older) of both genders who have suffered traumatic SDH. ASDH was defined as a hematoma in potential space between dura mater and arachnoid that was confirmed by a crescentic hyperdense lesion in head CT scan following trauma. Participants of all nationalities and setting were included. Participants with other head injury or focal lesions were excluded from this review.

The reviewed surgical interventions were decompressive craniectomy and craniotomy. Decompressive craniectomy was defined as a procedure removing a portion of skull temporary after clot evacuation. A craniotomy was defined as a procedure to evacuate clot and followed by cranioplasty. We excluded studies that did not describe the surgical procedure and combine the technique of interest with other technique.

The investigated outcome in this review was the Glasgow Outcome Scale (GOS) after the surgical procedure. GOS was dichotomized into favorable and poor outcomes. Favorable outcome was defined as GOS 4-5, while poor outcome was defined as GOS 1-3.

\section{Search strategy}

We extracted the eligibility criteria (PICO) into keywords using the Boolean operator. In this study, we used keywords ([craniectomy] AND [craniotomy] AND [ASDH] AND [outcome]) in PubMed, EBSCO, Google Scholar, and Directory of Open Access Journal database to find the eligible studies.

The study selection process was performed by two authors (EM and SA) to reduce the possibility of discarding relevant studies. The decision of another author was used when a disagreement occurred. Duplicate records were removed. Titles and abstracts were screened, and irrelevant studies were removed. Studies that passed the first screening were further evaluated for the compliance of the inclusion and exclusion criteria of this review. Finally, the studies were further evaluated for their quality before included in this review.

\section{Data collection process}

An electronic data collection form was used to collect data from each author. The collected data by each author will be merged and be managed with software Review Manager 5.3.

\section{Data items}

The data items were the author's name, year of publication, method, sample size, diagnosis of the participant, age, surgical technique, and GOS. GOS was dichotomized into favorable and poor outcomes. They were calculated for risk ratio $(R R)$ and were analyzed.

\section{Assessment of quality of a study}

Studies that complied with inclusion and exclusion criteria were assessed for their quality to ensure the validity and reliability of the studies. This process was done independently by two authors using a standardize critical appraisal tool to minimize the possibility of bias in study selection. The critical appraisal tool in this study was the Joanna Briggs Institute (JBI) critical appraisal tool based on study design. A decision of the third and fourth authors was used when a disagreement occurred.

The cutoff point was used to determine the quality of the study. The cutoff point in this review was half of the total score in each JBI critical appraisal checklist. The lowquality study was defined as a score below the cutoff point while conversely was termed as a high-quality study.

\section{Synthesis of result}

The RR of outcome was pooled and analyzed. Meta-analyses were performed using software Review Manager 5.3. The random-effect model was used because of high heterogeneity among studies.

\section{Results}

The systematic searching method resulted in six articles that met our inclusion and exclusion criteria 
(Figure 1). All six articles were observational cohort studies. We did not find any randomized clinical trial study comparing craniotomy and craniectomy. All six articles were considered as good quality based on our judgment. The summary of finding and complete characteristic of the study is shown in Tables 2 and 3.

From random-effect model analysis with high heterogeneity $\left(I^{2}=77 \% ; X^{2}=21.98\right)$, pooled $R R$

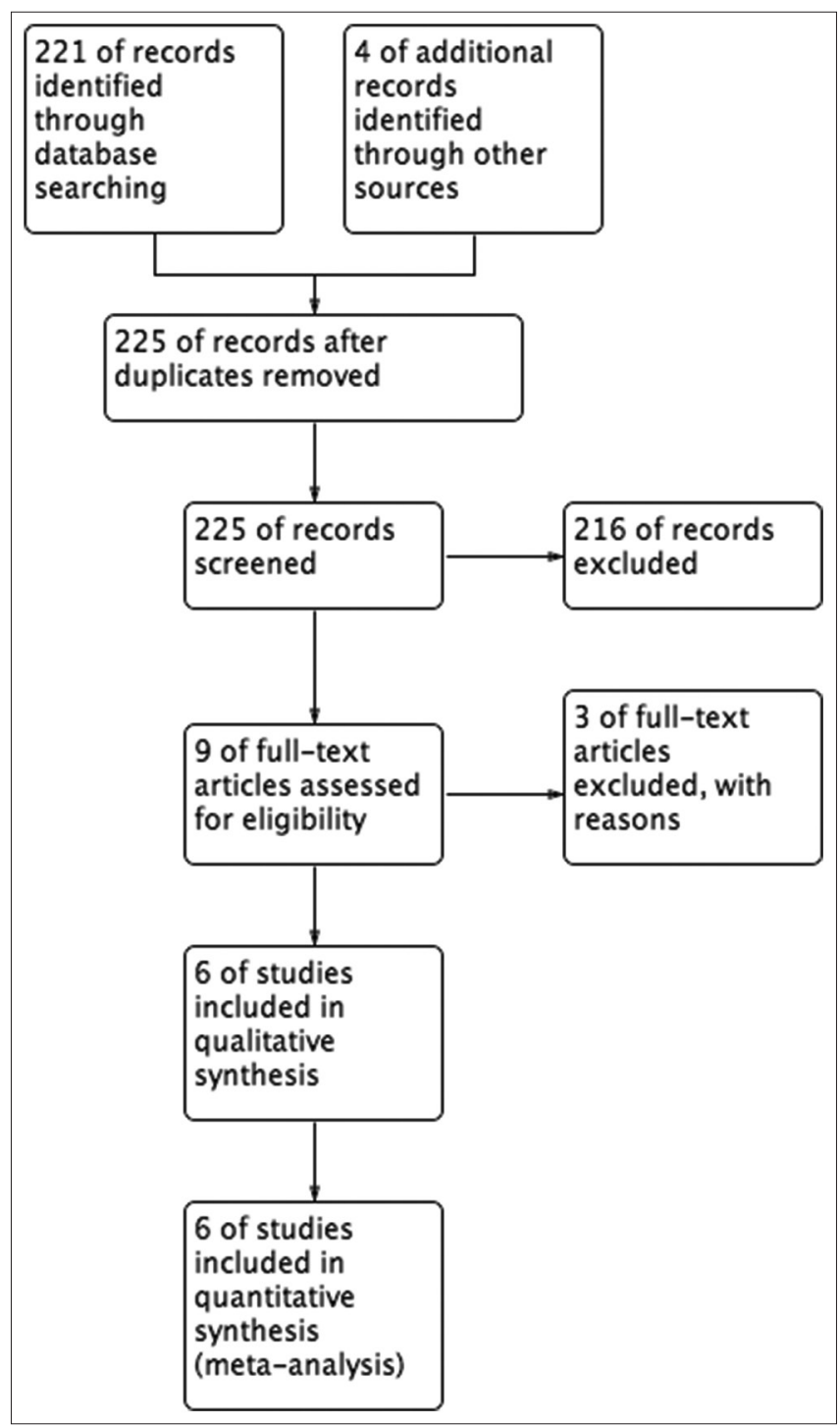

Figure 1: The PRISMA study flow diagram between craniectomy and craniotomy on poor outcome was 1.41 ( $p=0.02 ; 95 \% \mathrm{Cl}: 1.06-1)$ (Figure 2).

\section{Discussion}

TraumaticASDH is a major neurotrauma problem in the world. It causes primary brain damage because of direct compression to the brain and secondary damage mainly because of brain edema and ischemia due to compression. ASDH has been known for its high mortality rate. Several studies reported that initial GCS score, age, midline shift, and hematoma size are important clinical predictors of mortality [6], [7], [8], [9], [10].

The main objective of the surgical treatment is to relieve intracranial pressure by evacuating the hematoma with craniotomy followed by cranioplasty procedure. However, brain swelling can be uncontrolled during surgery, and cranioplasty cannot be done. Decompressive craniectomy seems to provide a better solution in that case because, in this procedure, the defect on the skull is kept open to provide "additional room" for the uncontrolled brain swelling, so the intracranial pressure remains normal. However, there is still debate which procedure provides a better outcome for traumatic ASDHs. At present, the surgical technique is based on the surgeon's preference.

From the pooled RR, we found that craniectomy provided worse outcomes compared to craniotomy as surgical treatment of traumatic ASDH. The pooled RR was 1.41 ( $p=0.02$ ), with high heterogeneity among studies. The result of this study is similar to other systematic reviews conducted by Phan et al. In their study, they found that craniectomy was associated with worse post-operative outcomes compared to craniotomy [11]. Based on our analysis of included studies, there are several factors that may contribute to the more unsatisfactory outcome of craniectomy for treating traumatic ASDH.

In a study by Tsermoulas et al., patients who were performed decompressive craniectomy tend to

Table 2: Summary of findings of the study sources

\begin{tabular}{|c|c|c|c|c|c|c|c|c|}
\hline Study author & Type of study & $\begin{array}{l}\text { Level of } \\
\text { evidence }\end{array}$ & Subject condition & Intervention & $\mathrm{n}$ & Control & $\mathrm{n}$ & Outcome \\
\hline Tsermoulas et al., 2016 & $\begin{array}{l}\text { Observational study, } \\
\text { prospective cohort }\end{array}$ & $1 \mathrm{~b}$ & $\begin{array}{l}\text { Patients above } 16 \text { years old with } \\
\text { traumatic acute subdural hematoma }\end{array}$ & $\mathrm{CR}$ & 69 & $\mathrm{CO}$ & 30 & $\begin{array}{l}\text { CR: } 41 \text { poor outcome, } \\
\text { CO: } 11 \text { poor outcome }\end{array}$ \\
\hline Chen et al., 2011 & $\begin{array}{l}\text { Observational study, } \\
\text { retrospective cohort }\end{array}$ & & $\begin{array}{l}\text { Patients with GCS score } 4-8 \text { and } \\
\text { subdural hematoma with thickness }>10 \\
\mathrm{~mm} \text { or a midline shift }>5 \mathrm{~mm} \text { on CT scan }\end{array}$ & $\mathrm{CR}$ & 60 & $\mathrm{CO}$ & 42 & $\begin{array}{l}\text { CR: } 27 \text { poor outcome, } \\
\text { CO: } 16 \text { poor outcome }\end{array}$ \\
\hline Vilcinis et al., 2017 & $\begin{array}{l}\text { Observational study, } \\
\text { prospective cohort }\end{array}$ & $1 \mathrm{~b}$ & $\begin{array}{l}\text { All adult patients diagnosed with acute } \\
\text { subdural hematoma causing brain } \\
\text { compression on pre-operative CT scan }\end{array}$ & $\mathrm{CR}$ & 249 & $\mathrm{CO}$ & 394 & $\begin{array}{l}\text { CR: } 212 \text { poor outcome, } \\
\text { CO: } 176 \text { poor outcome }\end{array}$ \\
\hline Woertgen et al., 2006 & $\begin{array}{l}\text { Observational study, } \\
\text { retrospective cohort }\end{array}$ & & $\begin{array}{l}\text { Patients with traumatic acute subdural } \\
\text { hematoma range } 15-91 \text { years old }\end{array}$ & $\mathrm{CR}$ & 69 & $\mathrm{CO}$ & 111 & $\begin{array}{l}\text { CR: } 41 \text { poor outcome, } \\
\text { CO: } 59 \text { poor outcome }\end{array}$ \\
\hline Li et al., 2012 & $\begin{array}{l}\text { Observational study, } \\
\text { retrospective cohort }\end{array}$ & & $\begin{array}{l}\text { All traumatic acute subdural hematoma } \\
\text { patients who underwent craniotomy or } \\
\text { craniectomy }\end{array}$ & $\mathrm{CR}$ & 50 & $\mathrm{CO}$ & 38 & $\begin{array}{l}\text { CR: } 29 \text { poor outcome, } \\
\text { CO: } 21 \text { poor outcome }\end{array}$ \\
\hline Wong et al., 2010 & $\begin{array}{l}\text { Observational study, } \\
\text { retrospective cohort }\end{array}$ & & $\begin{array}{l}\text { All traumatic acute subdural hematoma } \\
\text { patients who underwent craniotomy or } \\
\text { craniectomy }\end{array}$ & CR & 19 & $\mathrm{CO}$ & 22 & $\begin{array}{l}\text { CR: } 12 \text { poor outcome, } \\
\text { CO: } 7 \text { poor outcome }\end{array}$ \\
\hline
\end{tabular}




\section{Table 3: Characteristics of the studies}

\begin{tabular}{|c|c|}
\hline $\begin{array}{l}\text { Surgery for a } \\
\text { et al., 2016) }\end{array}$ & subdural hematoma: Replace or remove the bone flap? (Tsermoulas \\
\hline Methods & Prospective cohort \\
\hline Participants & Inclusion criteria \\
\hline & $\begin{array}{l}\text { Patient above } 16 \text { years old with traumatic acute subdural } \\
\text { hematoma }\end{array}$ \\
\hline & Underwent craniotomy or craniectomy \\
\hline & Exclusion criteria \\
\hline & Spontaneous acute subdural hematoma \\
\hline & Craniotomies for subacute or chronic subdural hematomas \\
\hline & Craniotomies for other types of injury \\
\hline Intervention & Intervention group \\
\hline & Decompressive craniectomy: 69 patients \\
\hline & Comparison group \\
\hline & Craniotomy with fixed flap and riding flap: 30 patients \\
\hline Outcomes & Primary outcome is Glasgow Outcome Scale at 6 months \\
\hline $\begin{array}{l}\text { Comparison } \\
\text { patients with }\end{array}$ & $\begin{array}{l}\text { niotomy and decompressive craniectomy in severely head injured } \\
\text { subdural hematoma. (Chen et al., 2011) }\end{array}$ \\
\hline Methods & Retrospective cohort \\
\hline Participants & Inclusion criteria \\
\hline & Patient with GCS score of $4-8$ \\
\hline & Subdural hematoma with thickness $>10 \mathrm{~mm}$ or midline shift $>5 \mathrm{~mm}$ \\
\hline & Exclusion criteria \\
\hline & Patient older than 70 years \\
\hline & $\begin{array}{l}\text { Had preexisting illness that limited life expectancy of less than } 1 \\
\text { year after ictus }\end{array}$ \\
\hline & Renal failure \\
\hline & Liver cirrhosis \\
\hline & Bleeding tendency \\
\hline & Penetrating injury \\
\hline & Hemodynamic instability \\
\hline & Injury $>24 \mathrm{~h}$ before admission \\
\hline & Bilateral pupillary dilatation \\
\hline & Previous neurologic condition \\
\hline & Underwent surgery for contralateral lesion \\
\hline & Patient with intracerebral hematoma larger than $2 \mathrm{~cm}$ in diameter \\
\hline Intervention & Intervention group \\
\hline & Decompressive craniectomy: 60 patients \\
\hline & Comparison group \\
\hline & Frontotemporoparietal craniotomy: 42 patients \\
\hline Outcomes & Primary outcomes are GOS at minimum 1 year after surgery. \\
\hline The Associat & f Surgical Method with Outcomes of Acute Subdural Hematoma \\
\hline Patients: Exp & ice with 643 Consecutive Patients. (Vilcinis et al., 2017) \\
\hline Methods & Prospective cohort \\
\hline Participants & Inclusion criteria \\
\hline & $\begin{array}{l}\text { Adult patients diagnosed with acute subdural hematoma causing } \\
\text { brain compression on pre-operative CT scan }\end{array}$ \\
\hline & Require emergent surgical evacuation of acute subdural hematoma \\
\hline & Exclusion criteria \\
\hline & $\begin{array}{l}\text { Underwent secondary decompressive craniectomy after evacuation } \\
\text { of acute subdural hematoma }\end{array}$ \\
\hline Intervention & Intervention group \\
\hline & Lateral or bifrontal decompressive craniectomy: 249 patients \\
\hline & Comparison group \\
\hline & Osteoplastic craniotomy: 394 patients \\
\hline Outcomes & Primary outcomes were GOS \\
\hline $\begin{array}{l}\text { Comparison } \\
\text { (Woertgen et }\end{array}$ & $\begin{array}{l}\text { 2006) } \\
\text { 200tomy and craniectomy in patients with acute subdural hematoma. }\end{array}$ \\
\hline Methods & Retrospective cohort \\
\hline Participants & Inclusion criteria \\
\hline & Patient with traumatic acute subdural hematoma \\
\hline & $\begin{array}{l}\text { Underwent large craniotomy or decompressive craniectomy with or } \\
\text { without duraplasty }\end{array}$ \\
\hline & Exclusion criteria \\
\hline & - $\quad$ 2 \\
\hline Intervention & Intervention group \\
\hline & Decompressive craniectomy with or without duraplasty: 69 patients \\
\hline & Comparison group \\
\hline & Large craniotomy: 111 patients \\
\hline Outcomes & Primary outcomes are GOS range from 4 months to 11 years \\
\hline $\begin{array}{l}\text { Outcome foll } \\
\text { with decomp }\end{array}$ & $\begin{array}{l}\text { evacuation of acute subdural hematomas: A comparison of craniotomy } \\
\text { e craniectomy. (Li et al., 2012) }\end{array}$ \\
\hline Methods & Retrospective cohort \\
\hline Participants & Inclusion criteria \\
\hline & $\begin{array}{l}\text { All patients with traumatic acute subdural hematoma who } \\
\text { underwent craniotomy or craniectomy }\end{array}$ \\
\hline & Require emergent surgical evacuation of acute subdural hematoma \\
\hline & Exclusion criteria \\
\hline & Non traumatic cases of acute subdural hematoma \\
\hline & Mini craniotomies \\
\hline & Acute on chronic subdural hematomas \\
\hline Intervention & Intervention group \\
\hline & Decompressive craniectomy: 50 patients \\
\hline & Comparison group \\
\hline & Craniotomy: 38 patients \\
\hline Outcomes & Primary outcomes are GOS at 6 months \\
\hline
\end{tabular}

Table 3: (Continued)

\begin{tabular}{|c|c|}
\hline $\begin{array}{l}\text { Surgery for a } \\
\text { et al., 2016) }\end{array}$ & ubdural hematoma: Replace or remove the bone flap? (Tsermoulas \\
\hline $\begin{array}{l}\text { Assessing th } \\
\text { and without } p\end{array}$ & $\begin{array}{l}\text { rological outcome of traumatic acute subdural hematoma patients with } \\
\text { y decompressive craniectomies. (Wong et al., 2010) }\end{array}$ \\
\hline Methods & Retrospective cohort \\
\hline Participants & Inclusion criteria \\
\hline & $\begin{array}{l}\text { All patients with traumatic acute subdural hematoma who } \\
\text { underwent craniotomy or craniectomy }\end{array}$ \\
\hline & Exclusion criteria \\
\hline & - $\quad$ \\
\hline Intervention & Intervention group \\
\hline & Decompressive craniectomy: 19 patients \\
\hline & Comparison group \\
\hline & Craniotomy: 22 patients \\
\hline Outcomes & Primary outcomes are GOS at 6 months after injury \\
\hline
\end{tabular}

have lower GCS, suffered more extracranial injuries, worse brain scans on admission, and worse prognostic score [12]. Vilcinis et al. [6] also have a similar result; patients with lower GCS score on admission, greater ASDH thickness, and midline shift tend to be performed craniectomy. Furthermore, Chen et al. stated that there was no difference of baseline characteristic of their study and found no significant difference of outcome between craniectomy and craniotomy [13].

The decision whether to perform craniectomy or craniotomy was surgeon dependent. However, intraoperative brain swelling after ASDH evacuation was an indicator to perform craniectomy also [6]. Craniectomy group tends to have a worse injury than craniotomy group. Patients who were performed craniectomy tend to have pupillary mydriasis and brain herniation. Brain herniation is a predictor of mortality in their study [14].

$\mathrm{Li}$ et al. reported that the operation technique was based on the surgeon's preference [15]. They reported that craniectomy tends to be performed in patients with obliteration of basal cistern and lower GCS score [15], [16]. Decompressive craniectomy tends to be performed on patients with worse conditions then craniotomy. Because of that, the result of this metaanalysis found that craniectomy has a poorer outcome if compared to craniotomy. We did not find an article that provides a similar baseline characteristic between craniotomy and craniectomy. This is the limitation of our study, so future studies should consider this problem.

Our meta-analysis result showed that craniectomy has a poorer outcome. However, this result should be interpreted cautiously because of high heterogeneity between studies, no randomized clinical trial study was included, and the possibility of baseline characteristic bias.

Based on our analysis, we suggested not to perform decompressive craniectomy as the primary first-line choice to treat ASDH. However, if brain edema is developing intraoperatively, the surgeon should perform a decompressive craniectomy immediately to prevent reoperation. Pre-operative midline shift, initial GCS, and presence of intraventricular hemorrhage can be predictors of post-craniectomy edema [17]. The first surgical planning for treating ASDH should be 


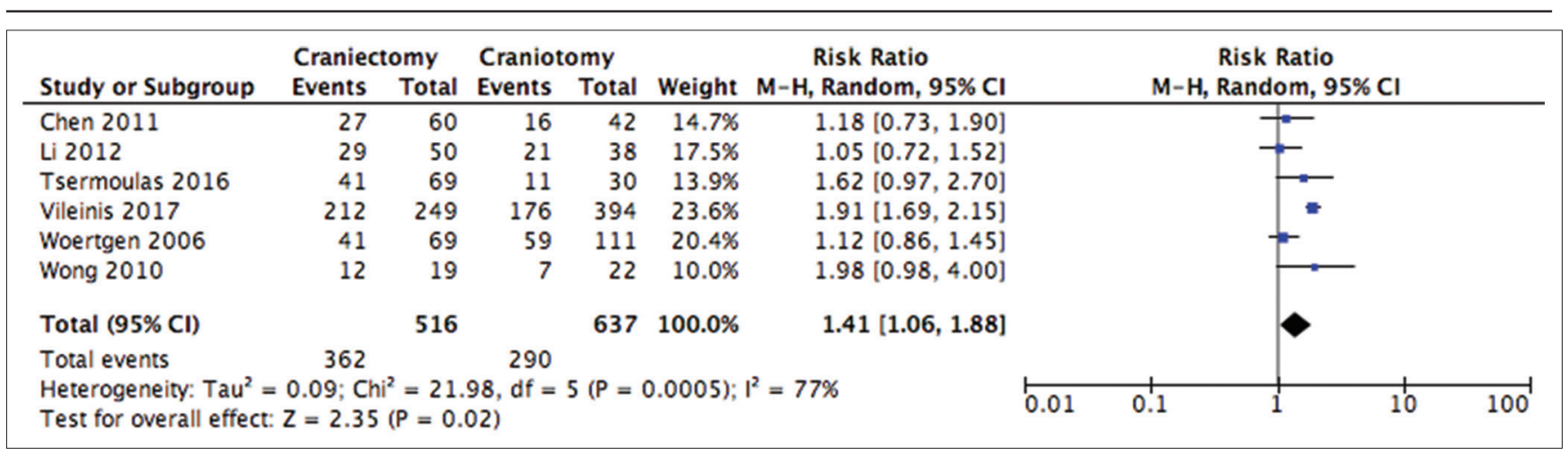

Figure 2: Forest plot comparing craniectomy and craniotomy. Cl: Confidence interval; M-H: Mantel-Haenszel

done with craniotomy technique; however, the surgeon should make preparation to perform decompressive craniectomy when severe brain edema occurred.

\section{Conclusion}

Craniectomy increases the risk of poor clinical outcomes in treating traumatic ASDHs. However, the interpretation should be done cautiously because of high heterogeneity between studies, no randomized clinical trial study was included, and the possibility of baseline characteristic bias. We suggest that the first surgical planning for treating ASDH should be done with craniotomy technique; however, surgeons should make preparation to perform decompressive craniectomy when severe brain edema occurred.

\section{References}

1. Vega RA, Valadka AB. Natural history of acute subdural hematoma. Neurosurg Clin North Am. 2017;28(2):247-55. PMid:28325459

2. Karibe H, Hayashi T, Hirano T, Kameyama M, Nakagawa A, Tominaga T. Surgical management of traumatic acute subdural hematoma in adults: A review. Neurol Med Chir (Tokyo). 2014;54(11):887-94. https://doi.org/10.2176/nmc.cr.2014-0204 PMid:25367584

3. Leitgeb J, Mauritz W, Brazinova A, Janciak I, Majdan M, Wilbacher I, et al. Outcome after severe brain trauma due to acute subdural hematoma. J Neurosurg. 2012;117(2):324-33. https://doi.org/10.3171/2012.4.jns 111448

PMid:22631691

4. Cooper PR, Hagler H, Clark K, Barnett P. Enhancement of experimental cerebral edema after decompressive craniectomy: Implications for the management of severe head injuries. Neurosurgery. 1979;4(4):296-300. https://doi. org/10.1097/00006123-197904000-00004

PMid:450227

5. Wilberger JE Jr., Harris M, Diamond DL. Acute subdural hematoma: Morbidity, mortality, and operative timing. J Neurosurg. 1991;74(2):212-8. https://doi.org/10.3171/jns.1991.74.2.0212

\section{PMid: 1988590}

6. Vilcinis R, Bunevicius A, Tamasauskas A. The association of surgica method with outcomes of acute subdural hematoma patients: Experience with 643 consecutive patients. World Neurosurg 1991;101:335-42. https://doi.org/10.1016/j.wneu.2017.02.010

7. Alagoz F, Yildirim AE, Sahinoglu M, Korkmaz M, Secer M, Celik $\mathrm{H}$, et al. Traumatic acute subdural hematomas: Analysis of outcomes and predictive factors at a single center. Turk Neurosurg. 2017;27(2):187-91. https://doi.org/10.5137/10195149.jtn.20651-17.0

PMid:27593776

8. Lenzi J, Caporlingua F, Caporlingua A, Anichini G, Nardone A, Passacantilli $\mathrm{E}$, et al. Relevancy of positive trends in mortality and functional recovery after surgical treatment of acute subdural hematomas. Our 10-year experience. $\mathrm{Br} \mathrm{J}$ Neurosurg. 2017;31(1):78-83. https://doi.org/10.1080/026886 97.2016 .1226253

PMid:27596026

9. Benedetto N, Gambacciani C, Montemurro N, Morganti R, Perrini P. Surgical management of acute subdural haematomas in elderly: Report of a single center experience. Br J Neurosurg. 2017;31(2):244-8. https://doi.org/10.1080/02 688697.2016.1244249

PMid:27760467

10. Bartels RH, Meijer FJ, van der Hoeven H, Edwards M, Prokop M. Midline shift in relation to thickness of traumatic acute subdural hematoma predicts mortality. BMC Neurol. 2015;15:220. https:// doi.org/10.1186/s12883-015-0479-x

PMid:26496765

11. Phan K, Moore JM, Griessenauer C, Dmytriw AA, Scherman DB, Sheik-Ali $\mathrm{S}$, et al. Craniotomy versus decompressive craniectomy for acute subdural hematoma: Systematic review and meta-analysis. World Neurosurg. 2017;101:677-85. https:// doi.org/10.1016/j.wneu.2017.03.024

PMid:28315797

12. Tsermoulas G, Shah O, Wijesinghe HE, Silva AHD, Ramalingam SK, Belli A. Surgery for acute subdural hematoma: Replace or remove the bone flap? World Neurosurg. 2016;88:569-75. https://doi.org/10.1016/j.wneu.2015.10.045 PMid:26523763

13. Chen SH, Chen Y, Fang WK, Huang DW, Huang KC, Tseng SH. Comparison of craniotomy and decompressive craniectomy in severely head-injured patients with acute subdural hematoma. J Trauma. 2011;71(6):1632-6. https://doi.org/10.1097/ ta.0b013e3182367b3c PMid:22027888

14. Woertgen C, Rothoerl RD, Schebesch KM, Albert R. Comparison of craniotomy and craniectomy in patients with acute subdural haematoma. J Clin Neurosci. 2006;13(7):718-21. https://doi. org/10.1016/j.jocn.2005.08.019

PMid:16904897 
15. Li LM, Kolias AG, Guilfoyle MR, Timofeev I, Corteen EA, Pickard JD, et al. Outcome following evacuation of acute subdural haematomas: A comparison of craniotomy with decompressive craniectomy. Acta Neurochir (Wien). 2012;54(9):1555-61. https://doi.org/10.1007/s00701-012-1428-8

PMid:22752713

16. Wong GK, Hung YW, Chong C, Yeung J, Ng SC, Rainer T, et al. Assessing the neurological outcome of traumatic acute subdural hematoma patients with and without primary decompressive craniectomies. Acta Neurochir Suppl. 2010;106:235-7. https:// doi.org/10.1007/978-3-211-98811-4_44

PMid:19812956

17. Nguyen HS, Janich K, Sharma A, Patel M, Mueller W. To retain or remove the bone flap during evacuation of acute subdural hematoma: Factors associated with perioperative brain edema. World Neurosurg. 2016;95:85-90. https://doi.org/10.1016/j. wneu.2016.07.067

PMid:27476687 